\section{JOAQUINA GARCÍA BALMASEDA Y SU CONTRIBUCIÓN PERIODÍSTICA AL UNIVERSO FEMENINO DECIMONÓNICO}

\author{
Ana María Gómez-Elegido Centeno \\ Universidad Complutense de Madrid. \\ anagomezelegido@hotmail.com
}

\begin{abstract}
Cómo citar este artículo/Citation: Gómez-Elegido Centeno, A. M. (2014). "Joaquina García Balmaseda y su contribución periodística al universo femenino decimonónico". Arbor, 190 (767): a138. doi: http://dx.doi.org/10.3989/ arbor.2014.767n3009
\end{abstract}

Recibido: 3 julio 2013. Aceptado: 6 abril 2014.

RESUMEN: Este artículo tiene por objeto el estudio de los textos publicados por la escritora Joaquina García Balmaseda (18371911) en la prensa femenina. A lo largo de su dilatada actividad como escritora profesional en los periódicos Joaquina García Balmaseda desarrolla un discurso que abarca todas las facetas del universo femenino del que ella misma participa. En esta escritura periodística encontramos numerosas páginas destinadas a la mujer donde se procura su instrucción y formación moral desde la infancia, textos que demuestran la necesidad de una educación integral y de una preparación para el ámbito doméstico y familiar pero también para su desarrollo, dedicación y realización en otros espacios sociales como el cultural y el profesional.

PALABRAS CLAVE: Joaquina García Balmaseda; escritura periodística; periodismo; literatura; educación; domesticidad; familia; cuestión femenina; cultura; siglo XIX.
JOAQUINA GARCÍA BALMASEDA AND HER JOURNALISTIC CONTRIBUTION TO THE NINETEENTH-CENTURY FEMININE UNIVERSE

Copyright: (c) 2014 CSIC. Este es un artículo de acceso abierto distribuido bajo los términos de la licencia Creative Commons Attribution-Non Commercial (by-nc) Spain 3.0.

ABSTRACT: This article looks at the texts Joaquina García Balmaseda (1837- 1911) published in the women's press. Throughout her lengthy career as a press writer she developed a line of discussion that embraces all aspects of the feminine universe to which she belonged. Her writings include an abundance of women's pages, addressing both their instruction and moral education from an early age. These texts demonstrate the need for a comprehensive education as well as training in the domestic and family realm. Nevertheless, women also needed to have an education that would aid their development, commitment and realisation in other social aspects, such as culturally and professionally.

KEYWORDS: Joaquina García Balmaseda; newspaper writing; journalism; literature; education; domesticity; family; women's rights; culture; 19th Century. 
Joaquina García Balmaseda es una de las autoras decimonónicas españolas pionera en la aventura de publicar en los periódicos. Hay que destacar precisamente el hecho de la pronta dedicación de la autora a esta tarea de escribir en prensa, en la cual se inicia en 1857, a los veinte años -nace en Madrid el 17 de febrero de 1837- y en la que persevera a lo largo de toda su vida. Ejerce la profesión de escritora en periódicos y llega incluso a dirigir uno de ellos, El Correo de la Moda, durante toda una década (1883-1893). El objeto de este artículo es estudiar el corpus de textos publicados por la autora en las publicaciones femeninas ${ }^{1}$. Joaquina García Balmaseda compatibilizará su temprana vocación periodística con el estudio de declamación en el Conservatorio, siendo actriz durante cuatro años en la compañía de Joaquín Arjona. Su vinculación con el mundo teatral continuará después como escritora de piezas dramáticas ${ }^{2}$ y de su experiencia sobre los escenarios quedará constancia en su obra periodística con artículos como "La mujer artista" (18-7-1872, no 27, pp. 209-10), en El Correo de la Moda, o bien en colaboraciones posteriores como las dedicadas a las grandes actrices Matilde Díez -“A Matilde Díez" (15-3-1883), poema publicado en Flores y Perlas-, y Teodora Lamadrid -“Las grandes actrices. Teodora Lamadrid" (4-5-1896, no 2003) en El Heraldo de Madrid-. Además de sus artículos en prensa Joaquina García Balmaseda publica varios libros de poemas y manuales instructivos, de labores, pedagógicos y morales ${ }^{3}$. El hecho de contraer matrimonio -el 2 de marzo de 1883, a los cuarenta y seis años- con el comandante Eustaquio González Marcos, no le hace abandonar su carrera literaria si bien hay que destacar que a partir de entonces aparecerá su firma en las páginas periodísticas como Joaquina Balmaseda de González ${ }^{4}$. Su dedicación a la tarea de escritora en prensa, aunque desde 1894 con el cierre de El Correo de la Moda disminuye ${ }^{5}$, prácticamente es una constante hasta pocos años antes de su muerte el 2 de marzo de 1911.

La mayor parte de sus artículos y textos periodísticos aparecen en la prensa femenina. Su producción se reparte entre las publicaciones dirigidas a la niñez y las dedicadas expresamente a las féminas, pero hay que considerar que si en las revistas infantiles los niños son los primeros receptores, detrás están las madres, que son quienes las compran y leen con sus hijos. Por tanto, las lectoras, de una u otra manera, son siempre las destinatarias de su discurso. Aquí sus renglones se multiplican desde las secciones de labores y modas, hasta los cuentos y artículos dirigidos a orientar el comportamiento y misión de la mujer, contribuir a su instrucción -educación- o simplemente ofrecer entretenimiento.

\section{LAS REVISTAS INFANTILES: EDUCACIÓN PINTORES- CA, LA AURORA DE LA VIDA, LA ILUSTRACIÓN DE LA INFANCIA Y LA ILUSTRACIÓN DE LOS NIÑOS}

Empieza a escribir en Educación Pintoresca. Periódico para niños ${ }^{6}$ (1857-1859) donde sus textos se centran en la educación de la infancia. En su primer artículo "Educación" (no 1, 1857, pp. 1-3) Joaquina García Balmaseda simula una escena en la que la directora de un colegio hace a sus alumnas la pregunta: “¿Qué es la educación?”. Con las respuestas se formula una definición de educación como formación integral englobadora de distintas facetas: religiosa, moral -"Todo aquello que hace nacer en nosotros buenos sentimientos y los fortifica; todo aquello que dirije y contiene nuestras pasiones, que cultiva nuestras virtudes, y perfecciona nuestras costumbres"7-, intelectual -"aquello que desenvuelve nuestra imaginación, perfecciona nuestro talento, y aumenta nuestra instrucción"8- y por último, económica - "Todo aquello que estiende nuestra capacidad y conocimiento en el manejo de la casa ú otros asuntos análogos"-. Se entiende esta última faceta como la educación doméstica, exclusiva de la mujer, consistente en enseñar las tareas de cuidar la familia y la casa. Constituye un artículo revelador de las directrices del pensamiento de nuestra autora, en consonancia con el de la época, que apunta la dimensión de la domesticidad en que se forma y vive la mujer española del S. XIX ${ }^{9}$. En esta línea pedagógica publica también "La linterna mágica. Para servir de esplicación a la lámina enciclopédica LA HISTORIA A VISTA DE PÁJARO"10 (no 31, 1858, pp. 7378), en donde, aprovechando el invento de la linterna mágica, hace una incursión por la Historia señalando su "significación religiosa" -recoge episodios de la Biblia hasta las Cruzadas-, destaca la importancia de acontecimientos como el descubrimiento de América, la imprenta de Gutenberg y el progreso del ferrocarril e introduce la lección moral de los medios para alcanzar la felicidad: "Es preciso, hijos míos, estudiar, trabajar y amar" (p. 77). Demuestra además la posibilidad de la educación por medio del entretenimiento -docere et delectare-: "el estudio puede hacerse agradable, y que para impresionar la inteligencia es preciso ante todo interesar el corazón" (p. 78). Se considera prioritaria la formación moral y muchas de las colaboraciones son relatos con protagonistas infantiles, sobre todo, niñas, a través de las cuales la autora pretende inculcar en sus lectores las virtudes y los buenos sentimientos, demostrando lo funesto de los malos com- 
portamientos. Es el caso de "La niña y la dalia" ( $n$ o 6, 1857, pp. 63-64) con moraleja sobre las apariencias y el orgullo, o bien "El mal humor" (no 16, 1857, pp. 184$88)$ ), sobre la amabilidad, lección dada por una madre a su hijo: "No olvides nunca lo que nuestro mal humor hace sufrir á las personas que nos rodean, y que la amabilidad, la igualdad de carácter, es uno de los mayores encantos que debemos, primero á la naturaleza, después á la educación" (p. 188). "La indolencia" (no 57, 1858, pp. 141-44) propone la aplicación y la constancia como vías de progreso en la vida y aconseja la obediencia a los padres, primeros maestros del niño: "ellos que os quieren con todo su corazón, os dirigirán, y obedeciéndoles vosotros recogeréis un día el fruto de vuestra docilidad" (p. 144). En "El niño y el gato" (no 69, 1858, pp. 333-35), una madre enseña a su hijo que no se debe ser egoísta. En estos cuentos la madre es figura fundamental que no solo inicia a los hijos en la vida moral, sino que también orienta y proporciona conocimientos y consejos útiles. Su misión va más allá de su función progenitora y se proyecta, a través de su función educadora, a un ámbito social y no solo doméstico, en esa preparación de los hijos para el mundo ${ }^{11}$. Así, las hijas son iniciadas en las labores propias de su sexo como en "Lecciones de la mamá. La muñeca” (no 34, 1858, pp. 115-20), donde una madre regala a su hija una muñeca y aprovecha para describir la laboriosidad de su proceso de fabricación. La madre resalta la especificidad femenina del hilado - "Hilar ha sido siempre en todos tiempos y países la ocupación favorita de nuestro sexo" (p. 117)-, pero también aprovecha para ir haciendo referencias históricas y observaciones sobre las maravillas de la naturaleza creadas por Dios, instruyendo a la niña. Hay otra serie de cuentos en que aparece la niña virtuosa que se apiada de la desgracia ajena y es ayudada por su madre en la tarea de socorro al necesitado. Son relatos con claros rasgos folletinescos. Es el caso de "Los niños buenos" (no 21, 1857, pp. 143-147), donde la protagonista es una niña de "precoz inteligencia" y "una alma pura" (p. 143), cuya buena conducta es premiada por "la Providencia que satisface siempre las necesidades de las personas bondadosas y devotas"(p. 147), o "La educación por las flores" ( $\mathrm{n}$ ㅇ 37 a no 39,1858 ), título de un relato en que una niña, junto a su madre, socorre a una familia humilde en un intento de demostrar la importancia de la educación desde la niñez en la potenciación de la inteligencia y la sensibilidad. En la primera de las entregas -( $n \div 037$, 1858, pp. 149-152)- se describe así la figura materna: "La madre de Luisa, que este era el nombre de la niña, poseía un talento y una instrucción nada comunes. Y se había propuesto formar por sí misma la educación de su hija. Con el tacto especial que solo tiene una madre, hacía trabajar su inteligencia" (p. 149). En este cuento se encuentra asimismo la idea de la educación como motor de la promoción social y dignificación de la mujer. También se proponen conductas ejemplares en artículos como "Santa Teresa de Jesús" (no 27, 1857, pp. 33-34), o “Niños célebres. Mozart" (no 85, 1859, pp. 153-155) ${ }^{12}$. De tema religioso, para orientar al niño hacia las creencias y prácticas religiosas, tenemos "El mes de María, ó Las flores de mayo" (no 5, 1857, pp. 49-50), "La flor del manzano" (no 32, 1857, pp. 92-93), cuento moral con reminiscencias evangélicas sobre el perdón, y "La fiesta de Navidad" (no 35, 1858, pp. 128-130) y "El nacimiento del niño Jesús" (no 83, 1858, pp. 129-132). "Fe, esperanza y caridad" ( $n$ 50, 1858, pp. 23-26) ilustra las tres virtudes teologales por medio de un cuento con niños como protagonistas. Sobre el valor del trabajo escribe "El estío" (no 14, 1857, pp. 157-158) y "La viña" (no 49, 1859, p. 16). Los textos son breves, sencillas ficciones con moraleja -con láminas e imágenes intercaladas- con las que se pretende desarrollar la curiosidad, instruir a niños y contribuir a su formación moral y religiosa. Asimismo publica la traducción ${ }^{13}$ de relatos de naturaleza ejemplarizante y educadora ${ }^{14}$.

La dedicación de Joaquina García Balmaseda al mundo de la moda se inicia en Educación Pintoresca donde se encarga de la sección "Modas de niños". Aquí ofrece la "Esplicación del Figurín que se reparte con esta entrega", si bien supera este cometido ya que en la mayoría de estos textos no se limita a describir la vestimenta infantil, sino que además recrea el escenario de los modelos y hace comentarios sobre la necesidad del buen comportamiento. Así en el no 58 (1858, pp. 156-157) describe primero el escenario:

Los jazmines y las azucenas esmaltan los jardines con su purísima blancura; los ardientes rayos del sol escitan á los pajarillos á entonar sus mágicos conciertos entre las ramas de los árboles, á cuya sombra acuden otros hechiceros pajarillos á confundir con los primeros sus agradables melodías: estas segundas avecillas son los niños, que al aproximarse la estación de las flores abandonan la jaula que más ó menos ricamente los ha retenido en prisión durante el invierno, y corren á reír y cantar por las frondosas alamedas del Retiro ó por el Salón del Prado (p. 156).

Y después completa el escrito con personajes, moda y virtud (bondad):

Estas lindísimas criaturas, que a su tierna edad manifestaban ya sus bellos instintos, estaban ata- 
viados con un gusto que hablaba muy alto en pró de la solícita madre. Llevaba la niña una blusita de popelín color de rosa, adornada por una tira blanca de cachemir, (...). El niño vestía una sencilla blusa de pelo de cabra, gris, abierta por delante adornada de arriba abajo por presillas de color negro,(...) Estos sencillos vestidos que hemos descrito, realzaban notablemente los encantos de aquellos hermosos niños, que llevaban además una prenda que siempre es de moda; que sin ella los mas bellos trajes parecen incompletos, y que cual ningún adorno aumenta la hermosura de los niños. Quereis saber cuál, lectores mios? Era la espresión de bondad que sus buenas cualidades imprimían en sus rostros infantiles. Estas son, niños mios, nuestro mejor atavío; ellas realzan mucho mejor que los adornos vuestros encantos" (pp. 156-157).

La sección "Labores"15 se dirige exclusivamente a las lectoras haciendo una distinción de educación y funciones entre niños y niñas ${ }^{16}$ :

No os enojeis, ante todo, jóvenes lectores, si al leer su epígrafe comprendeis que este artículo no está escrito para vosotros: en los históricos, en los de física, geografía é historia natural, llevais la mejor parte, y justo es que alguna vez nos dirijamos exclusivamente á las niñas, á esas preciosas compañeras vuestras, que sin participar de los juegos violentos, propios de vuestro sexo, pasan quizá sus horas en hacer vestidos á sus muñecas, dando así ya muestras inequívocas de la laboriosidad que un día ha de constituir su más bello adorno.

Desde que apareció nuestro periódico, ofrecimos escribir para ellas novelitas morales y artículos de labores: de entonces acá, queridas niñas, venimos cumpliéndoos lo primero que tiende a formar vuestro corazón, y desenvolver vuestras bellas cualidades, que permanecerían encerradas en el fondo del alma como la flor en su capullo, si la educación, á semejanza de benéfico rocío, no la hiciera entreabrir sus hojas y exhalar su aroma. (p. 221, en no 62,1858 , pp. 221-123)

Con el artículo pretende: "haceros agradables á par que las virtudes, las labores de vuestro sexo, fuente de la economía doméstica, símbolo de las pacíficas tareas, que la mujer está llamada a desempeñar en la sociedad, y á veces recurso decoroso que ha salvado á multitud de familias de la miseria o la degradación." (p. 222). Aquí vemos de nuevo la importancia otorgada a la economía doméstica como fuente de la armonía familiar que se encarga a la mujer, en este caso representada por las labores, contemplando también su ejercicio como tarea profesional femenina. En la dedicatoria de la sección se hace mención especial a las madres -"á esos séres benéficos, que la Providencia colocó a vuestro lado para guiaros y protegeros" (p. 222)- a las que se pide su colaboración. En cuanto a la sección "Juegos de niñas" tenemos diversos textos en que inventa un hilo argumental sobre la estancia de un grupo de niños veraneantes describiendo sus diferentes juegos. La serie concluye con el más representativo de la feminidad, la muñeca -no 93, 1859, pp. 249-51-, por permitir el desarrollo de las capacidades más propias de la futura mujer. El conjunto de estos textos será la base de su obra La madre de familia. Diálogos instructivos sobre la religión, la moral y las maravillas de la naturaleza (1860), seleccionado como libro de lectura en las escuelas de primera enseñanza.

En sus escritos de La Aurora de la vida. Único periódico ilustrado dedicado a niños de ambos sexos (18601862 ) está presente el mismo afán pedagógico y moralizador que practica en Educación Pintoresca. Su colaboración se inicia con un cuento moral y cristiano, "El don que Dios recompensa" (8-6-1861, pp. 6-9), donde la historia es soporte de la moraleja final: "el que bien obra, por la sola satisfacción de su conciencia, es el que merece la recompensa de Dios" (p. 9). Asimismo hallamos cuentos traducidos en la misma línea edificante ${ }^{17}$. También escribe en "Labores", donde además de explicar el tipo de bordado presentado en la lámina de la revista, aprovecha para recalcar su condición femenina -"forman parte de la educación de la mujer" - distinguiendo entre las ocupaciones del niño y la niña (13-6-1861, p. 45). Y de carácter didáctico y con propósito cultural divulgativo publica "Explicación del enigma histórico y geográfico. Strasburgo" (16-91861, pp. 162-163) -con grabado intercalado- donde describe el entorno geográfico, la historia y arquitectura de esta ciudad, cita a Gutenberg y destaca la importancia de la imprenta para la cultura. Insiste en este avance en muchos de sus textos reconociendo la relevancia de este invento para la divulgación de las letras haciendo mención al periódico -Joaquina García Balmaseda es consciente del poder difusor del soporte periodístico para la formación y la educación-. Es significativo que se detenga en contar cómo la hija del constructor del campanario de la catedral fue la que terminó esta obra, indicando la aportación femenina a otros campos distintos del de la domesticidad.

En otras publicaciones infantiles como La llustración de la infancia ${ }^{18}$ reedita trabajos aparecidos en otras revistas y en La llustración de los niños ${ }^{19}$ incluye un cuento, "El premio del bien obrar. Cuento de niños" (1-10-1879, II, pp. 102-104 y pp. 115-116), donde va- 
lora la importancia de las narraciones populares como riqueza moral de los pueblos. Dirigiéndose explícitamente a sus lectoras relata uno de estos cuentos que oyó de pequeña, donde la caridad resulta ser la cualidad suprema.

\section{LAS REVISTAS FEMENINAS: LA FLORESTA, LA EDU- CANDA, EL CORREO DE LA MODA}

El total de las colaboraciones de Joaquina García Balmaseda en La Floresta ${ }^{20}$ (1857) se circunscribe a la moda y en ellas firma por primera vez como Aurora Pérez Mirón. La originalidad de sus escritos se debe a que no se limita a efectuar la somera descripción de tendencias, modelos, telas, formas y colores, sino que construye muchas veces, a modo de escena teatral -no olvidemos su vinculación con este mundo-, todo un cuadro en que sitúa la imagen femenina, realizando una recreación literaria de la moda con paisaje madrileño y comentario ameno. Así, en el no 3 (24-51857, p. 39) anuncia la moda de primavera con esta introducción sobre la llegada de la nueva estación a Madrid:

Cuando los coliseos van cerrando sus puertas en la coronada Villa, el gran teatro de la naturaleza cambia su triste decoración de nubes y brumas, por las alegres y risueñas de bosques y jardines. (...) El caballero Febo se presenta en escena con su espléndido traje recamado de oro á saludar á la señorita Primavera, que le aguardaba ya impaciente con su encantadora túnica verde, con disposiciones de lilas y pensamientos.

La Moda no podía faltar á esta función, ni nosotros sus cronistas dejar de apuntar las novedades que prepara para las grandes fiestas de la Naturaleza

Después informa de la tendencia de complementos -sombreros, manteletas y chales-, retrata al público a su salida del teatro y espectáculos de Madrid, y sigue el recorrido de las féminas desde la plaza de toros hasta la estación del ferrocarril. Describe y aconseja determinada indumentaria -“Como graciosa novedad de la Moda, recomendaremos a nuestras lectoras un vestido de glassé negro cuyo cuerpo es una basquine o chaqueta de falda extremadamente larga y de mucho vuelo" - y termina con el comentario de obras teatrales.

En La Educanda ${ }^{21}$ (1862-1865) su producción es muy prolífica, de manera que hay ocasiones en que en un mismo número aparecen varios escritos suyos. Publica artículos sobre la educación femenina, como en el no12 "La mejor educación" (28-2-1863), donde distingue dos tipos: la que hace triunfar en sociedad y la que permite triunfar en la vida, destacando esta última como la verdaderamente importante y moral. Defiende la idea de que la educación en las virtudes femeninas -dulzura, modestia y resignación- corresponde a la madre, que asimismo debe procurar "añadir á la educación moral de su hija la educación social que brilla y seduce" (p. 90), consiguiendo así el prototipo de mujer y madre ideal. De nuevo hallamos la publicación de relatos traducidos y otros reeditados ${ }^{22}$ y su firma en la sección de "Labores". Asimismo tenemos su seudónimo de Aurora Pérez Mirón en el apartado final de "Modas" con explicaciones del figurín. En 1865 se encarga de "Revista de Modas".

Junto con otros artículos, también publica aquí dos relatos: "Existencia ignorada", por entregas -(82-1864, no57, pp. 39-40; 16-2-1864, no 58, pp. 4748; 24-2-1864, no 59, pp. 54-56)- cuya protagonista es una joven virtuosa que saca adelante a su familia ayudando en trabajos de labores, y la larga narración “Clemencia" -iniciada en el no 102 (16-1-1865) y continuada en los números: 103, 105, 106, 108-110, 112114, 116-118, 120- 123 (24-6-1865)- donde tenemos dos personajes femeninos que ejercen una profesión: una actriz, Laura Monti, retirada por su marido de los escenarios a los que vuelve después para ayudarle a salir de la ruina, y el de la heroína que da nombre a la obra, Clemencia, joven que renuncia a una brillante carrera de cantante para cuidar y mantener a su familia como maestra de canto.

El Correo de la Moda ${ }^{23}$ es la publicación en que Joaquina García Balmaseda desarrolla una colaboración más dilatada y prolífica, además de convertirse en su directora -tras la muerte de la anterior, Ángela Grassien 1883 y hasta el 26 de diciembre de 1893. Encontraremos su pluma en diversas secciones: "Revista de Modas"-desde 1866 hasta el 18 de marzo de 1881 y después desde el 24 de enero de 1882 hasta 1886y en "Modas" -como Aurora Pérez Mirón-, "Labores", "La vida en sociedad" y "La vida en familia" -donde firma como La Baronesa de Olivares"24- y "Revista de Madrid" -donde figura como Adela Samb-.

En "Revista de Modas" adopta el esquema de escritura iniciado en La Floresta (1757), de manera que el texto no responde únicamente a una escueta presentación de modelos y complementos, sobrepasándose literariamente la crónica de moda. Así en el no 640 (30-4-1866, p. 121-122) escribe esta amplia y colorista introducción:

Quién no ha sentido en cualquiera de los días del florido mes que hoy termina dilatar su alma, re- 
montar su pensamiento, creyéndose por un instante trasladado á otro mundo de placer, de galas, de armonías y perfumes, al asomarse simplemente á los jardines de nuestro paseo de Recoletos? Las colindas, las lilas, los jacintos y las bretañas embalsamaban el ambiente; las mas distinguidas damas competían en lujosos trenes y atavíos, y si á esto se unían los inspirados acordes de los magistrales conciertos del señor Barbieri escapándose por las cien ventanas del circo del PRÍNCIPE ALFONSO, o los de las bandas militares celebrando la inauguración de una obra que la arquitectura levanta para honra de las letras españolas, ¿decid si no debía elevarse el pensamiento y el corazón, y si no quiso Dios elevar en un solo punto, en el paseo de Recoletos, los perfumes, las armonías, el lujo, la hermosura, la nobleza y las glorias de las artes y las letras? Atravesar un dilatado jardín antes de entrar en el Circo á escuchar las melodías de Beethoven, de Thomas ó de Rossini, era disponer el corazón á las impresiones que le habían de conmover; penetrar en el cercado donde iba á colocar su majestad la primera piedra para la Biblioteca y Museo Nacional, por entre las flores, los trenes de la nobleza, el lujo de la aristocracia, el esplendor del ejército y el entusiasmo de un pueblo apiñado, era levantar el pensamiento hasta la grandeza de la solemnidad. Como en nuestro número anterior os hablamos ya de estas fiestas, nos limitaremos solo á deciros que ha hecho la Moda para estos actos notables esfuerzos, presentándose digna de fijar la atención. (p. 121)

En "Revista de Madrid" la firma de Adela Samb comienza en 1883. Ahora comenta los distintos acontecimientos sociales de la capital. Así el día 26-6-1884 (p. 191) registra las diversiones durante ese mes -“corridas de toros extraordinarias; conciertos al aire libre; bailes campestres; verbenas; fiestas nocturnas en palacios iluminados con luz eléctrica ${ }^{25}$; bodas aristocráticas; exposiciones artísticas y paseos en los bosques deliciosos como solo se encuentran en la capital en esta época del año."-. Da cuenta de las actividades culturales como una exposición de pinturas y del teatro, y termina reseñando la función "verificada en el artístico salón de la señora viuda de Piquer" y cuyos fondos se destinaron a "la construcción de un mausoleo destinado á los célebres artistas Matilde Díez y Julián Romea". En "Revista de Madrid" (26-4-1885, pp. 94-95), con motivo de la Semana Santa, destaca la doble faceta de las señoras: "Mezcla singular de frivolidad y misticismo, de ligereza y de sensatez, la mujer actual practica la obligación dominante del día, y lo mismo se juzga obligada á bailar en carnaval que á rezar en cuaresma" (p. 95). Se hace eco también de los actos presididos por la familia real, de algunas celebraciones de San José y de la reunión en casa de la viuda de Piquer con sus veladas musicales y teatrales. En la sección "La vida en sociedad" 26 también recrea costumbres y hábitos sociales y ofrece diversos consejos prácticos a las señoras y jóvenes para su adecuado comportamiento. En esta sección tratará temas tan diversos como los viajes de recreo, los balnearios,... Enseñará a escribir una carta en "Las cartas" (18-111884) a "la mujer vulgar, a la que vive consagrada al cuidado de su familia, la joven que comienza a ocupar un modesto lugar en el mundo"27. Ofrecerá apuntes domésticos y aleccionará sobre el cultivo de las virtudes y buenas cualidades -amor al prójimo, discreción, sencillez y pudor-. En "Las comidas" (2-3-1886, p. 71) describe las innovaciones en las comidas de etiqueta: invitaciones, indumentaria, protocolo ${ }^{28}, .$. Y en "La vida en sociedad" (2-6-1886, p. 167) trata sobre el comportamiento de la mujer madura y critica la coquetería ${ }^{29}$ : "la coqueta no abriga ninguno de los sentimientos que son honor de su sexo, y sacrifica á la sociedad las más caras afecciones del corazón". En "La vida en familia" la Baronesa de Olivares brinda ideas, consejos, da instrucciones y trata de "escribir sobre asuntos que sean de alguna utilidad para la mujer en su vida práctica é intelectual", como establece en "Condiciones precisas á un ama de casa" (2-12-1884, p. 359), donde ofrece orientaciones sobre las cualidades morales que deben "adornar á un ama de casa, cargo que exije tesoros de inteligencia, de cariño, de abnegación" ${ }^{30}$. Muchos de estos artículos son textos de su libro La mujer sensata. Educación de sí misma (1882).

Tenemos también en El Correo de la Moda cuentos como "La casa del indiano. Tradición popular" (2-91877 , p. 263), inspirado en una leyenda navarra de amor contrariado por el orgullo; "Al pié de la Cruz" (10-4-1884, pp. 106-107) es una reflexión religiosa sobre la Semana Santa y "La única felicidad" (10-101884 , p. 302) es una meditación basada en un ejemplo femenino de entereza y resignación. En "Semilla que no se pierde. Cuento de color de historia" (2-11886, pp. 6-7) demuestra cómo se premian las buenas obras y en "Una carta perdida" (2-3-1886, p. 71) reproduce la carta en que una mujer ofrece el modelo de felicidad familiar.

También escribe otros artículos interesantes por la nueva perspectiva desde la que considera a la mujer, a la que se presenta desde su vertiente profesional como trabajadora fuera del hogar y como escritora e intelectual. En "La mujer artista” (18-7-1872) $)^{31}$ 
muestra los sinsabores de esta fémina ante el posible conflicto entre las esferas familiar/doméstica y profesional:

Y sin embargo, sin negar que la felicidad doméstica sea compatible con la celebridad de la mujer, debo haceros comprender que en muchas ocasiones sacrifica la primera á la segunda; que muchas veces encuentra en esa vida de ovaciones todas las amarguras de la vida del hombre, sin alcanzar ninguna de sus ventajas; sacrificando en aras de esa mentida gloria la paz del hogar, el reposo de la familia, las emociones íntimas, la ternura de la espansión, esa dicha que vive en el retiro y el misterio (p. 209)

Reconoce la fortaleza de las armas femeninas proclamando la ausencia de inferioridad respecto al hombre: "porque la naturaleza que dio distintas armas para luchar al hombre y a la mujer, no hizo las de esta inferiores por fortuna"(p. 209). Cada sexo tiene su espacio y si el ejercicio de las virtudes femeninas tiene en el hogar su principal campo de proyección, este no es el único ${ }^{32}$. Analiza el perfil de la mujer artista que desarrolla su sensibilidad y cualidades en un nuevo ámbito, señalando las grandes exigencias de sus responsabilidades profesionales. También destaca la mayor dificultad de la mujer frente al hombre para triunfar en los círculos artísticos:

$Y$ esto sin contar con los esfuerzo que representa alcanzar un nombre en el mundo del arte á la mujer á quien se cierran todos los caminos de abordarle. El hombre desde que nace vive para el mundo y para la ciencia: la mujer cuando se siente artista empieza á penetrar los misterios del arte, intenta los primeros estudios de él. iQué esfuerzo tan gigante! Y sin embargo no por esto se le exige menos: que presente un lienzo en una exposición, y si no es el primero en mérito no alcanzará premio por estas solas consideraciones. ¡Tiene que luchar como mujer y no alcanza sino como hombre!" (p. 210)

En "La lectura en la mujer" (26-4-1880, pp. 123124) recomienda la lectura a las jóvenes como fuente de conocimiento, recordando su propia experiencia: “iCuántas lecturas que fuéron en mi infancia recreo de mis padres, se han convertido en rico manantial de conocimientos, señalándome estudios que nunca hubiera soñado mi modestia!" (p. 123). Debido al carácter autodidacta de muchas de las jóvenes de la época, la lectura desempeña un papel fundamental para su formación y Joaquina García Balmaseda se dirige a las madres como pilares fundamentales en la educación lectora de las hijas y así, junto a los estudios habituales en "las jóvenes de buena sociedad", como la música, la pintura, los idiomas, propone el cultivo de la lectura "arte útil en la familia y en la sociedad". Señala la facilidad de la época para la adquisición de buenos libros y destaca la relevancia de la función divulgadora de la prensa -reconoce por tanto su propia labor como escritora en revistas- en estas tareas culturales. La lectura es el mejor hábito al que la madre puede aficionar a sus hijas como salvaguardia de la futura sabiduría femenina y así concluye:

que la madre, vigilante perpetuo de sus hijas, (...), escoja lecturas propias para ellas y las acostumbre a leer en alta voz, como recreo digno de una inteligencia clara; que en la ancianidad, cuando tiene que prescindir de los recreos que la sociedad ofrece, ella será la primera en bendecir su buen acuerdo, escuchando de bocas de sus hijas conceptos discretamente sentidos y discretamente interpretados, que le harán vivir en el mundo de la inteligencia (p. 124).

Dedicados a otras escritoras contemporáneas, donde se muestra el papel de la mujer en la cultura, tenemos dos artículos: "Ángela Grassi" (26-9-1883, p. 182) y "Rosario Acuña en el Ateneo científico y literario de Madrid" (2-2-1884, 17, p. 134). El primero se escribe con motivo de la muerte de Ángela Grassi. Aquí, Joaquina García Balmaseda se refiere a la obra y la vida de la escritora subrayando las excelencias de sus textos periodísticos y literarios y la ejemplaridad de su trayectoria vital. Se aprovecha para reivindicar, teniendo como parangón a la Grassi, la instrucción de la mujer y su desarrollo en los ámbitos doméstico, artístico-literario y periodístico:

Ángela Grassi poseía el francés y el italiano, dominaba el divino arte de la música, y cosa más extraña aún, tenía un título de maestra para dedicarse a la enseñanza, ejemplo que viene a destruir una vez más la vulgaridad de que las señoras consagradas a las artes y a las letras, son refractarias a las labores propias de su sexo

"Rosario Acuña en el Ateneo científico y literario de Madrid" (2-2-1884, 17, p. 134) es la crónica de la actuación de esta escritora, colaboradora también de El Correo de la Moda, en esta institución literaria. Joaquina García Balmaseda se muestra reivindicativa respecto a la intervención de la mujer en la vida cultural, recordando su propia contribución. Empieza informando acerca del acto celebrado y de su decisión de acudir a pesar de la desconsideración de no haber sido invitada: 
Con planta vacilante y conturbado espíritu, acudimos la noche del 19 de Abril al Ateneo Científico y Literario, y no ciertamente porque hubiéramos recibido cortés invitación para ello; ni la Sociedad que cuenta en su seno las primeras ilustraciones del país, ni la distinguida escritora que iba á darnos en aquella noche gallardas muestras de su ingenio, fijáronse en que al estar la velada á cargo de una señora, las otras, que con más ó ménos acierto toman parte en las tareas literarias de su tiempo, tendrían natural deseo y legítimo orgullo en escucharla.

Posteriormente hace una crítica positiva a la actuación de la autora y reclama la representación femenina española en el mundo de la ciencia y el arte:

Modesta en su decir, sabiendo avalorar los conceptos más culminantes sin énfasis declamatorio: profunda en la intención; entonada y correcta siempre: acometiendo con audacia teorías de las modernas escuelas filosóficas, y haciendo ver que el entendimiento de la mujer, cuando se cultiva, es susceptible de todos los estudios, de todas las creaciones, de todos los arrebatos de la inspiración, y que así pueden fundirse en el crisol de su ingenio las ideas del arte, como las de ciencia ó filosofía social, Rosario Acuña consiguió un triunfo, que quedará consignado en los anales de la primera Sociedad literaria de la nación, y en la historia literaria de la mujer española.

A continuación glosa las conquistas intelectuales de la mujer y aprovecha también para hacer notar cómo ella misma ha participado en destacadas instituciones culturales junto a otras pioneras que detalla en nota a pie de página:

En la época moderna, la mujer ha conquistado aplausos en el teatro, y en la tribuna, en la literatura y en las artes, y si Rosario Acuña ha logrado hacer oír su hermosa voz donde solo llegaron hasta hoy los hombres de ciencia y de saber, otras han dejado escuchar la suya en el Paraninfo de la Universidad Central ó en el Fomento de las Artes (1), y algunas, sucesoras de la gloria de Gertrudis Gómez de Avellaneda, han conquistado, al lado de la autora de Rienzi, aplausos en la escena ${ }^{33}$

Termina insistiendo en la importancia del triunfo de Rosario Acuña por su significación en la trayectoria del avance cultural femenino: el triunfo de nuestra querida amiga nos basta para sentir legítimo orgullo; a él se asociarán, de seguro, cuantas señoras cultivan las letras en España; y nosotros, desde este humilde Semanario, escrito por la mujer y para la mujer, le enviamos la más sincera expresión de reconocimiento, por haber tenido el valor de demostrar una vez más lo que valen su inspiración y su constante estudio. Las lectoras de $E L$ CORREO DE LA MODA, que leen sus bellos artículos titulados En el campo, no serán tampoco indiferentes á su reciente triunfo, y por eso no queremos dejar de consignar en nuestro periódico, (...), que el nombre de Rosario Acuña ha conseguido grabarse una vez más entre todos aquellos que avaloran las letras españolas

\section{CONCLUSIONES}

Joaquina García Balmaseda en su dilatada presencia en la prensa despliega una escritura que, siempre coherente con su propia ideología conservadora y católica, define la misión de la mujer que vela por una sociedad cristiana cuyo norte es la familia, pero también reivindica la importancia de la instrucción y la educación, de la preparación y de la formación intelectual desde la niñez para procurar el desarrollo propio e independiente de la mujer -desarrollo profesional y laboral-. En la variedad de sus textos que comprende desde sus artículos pedagógicos, pragmáticos y morales, hasta las creaciones literarias de poemas y relatos edificantes -muchos de ellos protagonizados por niñas o mujeres- se refleja un universo femenino que es el referente constante de sus páginas en los periódicos. Si en sus primeras colaboraciones la principal preocupación es la educación y la formación integral de la niñez, en sus posteriores renglones dirigidos a la mujer sigue sin descuidar ninguno de los aspectos fundamentales del ámbito femenino, de su instrucción complementaria y su forma de vida. Joaquina García Balmaseda desde su propia misión de escritora profesional en los periódicos utiliza este medio de difusión para hacer llegar a sus lectoras la necesidad de la mejora y el perfeccionamiento del universo femenino desde el modelo de mujer virtuosa y doméstica hasta el que reivindica la proyección social y cultural femenina. 
1 Sobre la obra periodística de Joaquina García Balmaseda se sigue la bibliografía de Carmen Simón Palmer (1991, pp. 284-293).

2 Genio y figura (1861), Un pájaro en el garlito. Comedia en un acto y en prosa (1871), Donde las dan..., Proverbio en un acto y en verso (1868).

3 Los poemas se recogen en los volúmenes Entre el Cielo y la Tierra. Poesías, precedidas de un prólogo del Sr. D. Manuel Cañete, (1868) y en Ecos de otra edad (1907). La prensa es fundamental como soporte de publicación de sus poemas. A partir de los años 70 , la mayor parte de sus colaboraciones son composiciones poéticas que aparecen en las siguientes publicaciones: $L a$ Educanda, La América, El Correo de la Moda, La Voz de la Caridad, El Amigo de las Damas, La Madre de Familia, La Familia, Los Niños, La llustración de la infancia, El Eco de Europa, La Academia, La llustración de los Niños, La niñez, La Crónica musical, La Aurora de la vida París-Charmant-Artístico, La semana Madrileña, Flores y Perlas, El Museo Literario. En cuanto a los manuales escribe: La madre de familia. Diálogos instructivos (1860), La mujer laboriosa, novísimo manual de labores que comprende desde los primeros rudimentos de costura hasta las más frívolas labores de adorno (1884), La mujer sensata. Educación de sí misma (1882), galardonada en el Congreso pedagógico de 1883, antología de textos periodísticos, Historia de una muñeca escrita por ella misma: libro de utilidad y recreo para las niñas (1889).

4 Es interesante la interpretación que C. Simón Palmer (1986, p. 594) ofrece de este hecho: “... en España es un número escaso el de aquellas mujeres que se ocultan tras un seudónimo masculino para escribir, en contra de lo que cabría suponer antes de conocer el contenido de sus obras. Van a preferir añadir el apellido de su esposo tras el primero suyo y aparecen así Robustiana Armiño de Cuesta, Pilar Sinués de Marco, Josefa Estévez de G. del Canto, etc. Pensamos que la intención existía cuando utilizaban el «de» en la portada de sus libros y era la de indicar de un modo indirecto, pero seguro, a los posibles compradores que el contenido del libro escrito por una mujer casada no podía menos que responder a unas ideas de "sana» moral, aunque se debiera a pluma femenina. Esta preocupación por demostrar su femineidad y que se mantienen dentro del orden establecido es una constante en la mayoría".

5 Andalucía (1895), Barcelona Cómica (1895), Pro-patria (1895), La Moda Europea (1899), El Heraldo de Madrid (1896), El Oriente de Asturias (18991900), Gente Vieja (1904) y El Álbum Hispano-Americano (1906) fueron cabeceras que acogieron esporádicamente sus textos en esta última etapa.

6 Es un periódico para niños con grabados y láminas. Presenta el subtítulo de "publicación para niños" y publica artículos de ciencias naturales y físicas, geografía biografías breves de personajes célebres, historia, descripciones de monumentos, así como cuentos y poemas, fábulas, leyendas, pensamientos, etc.

7 Se reproduce la ortografía original de los textos de los periódicos en todas las citas.

8 Escribe Catherine Jagoe: "La sexualización y polarización de los términos educación e instrucción, el primero moralreligioso y el segundo intelectual-social, iba a convertirse en el lema del XIX" (1998, p. 116).

9 Sobre esto establece Alda Blanco: "Los textos literarios y ensayos periodísticos de las escritoras de la domesticidad de la época isabelina, por lo tanto, encierran propuestas, argumentaciones $\mathrm{y}$ ejemplos acerca del ideal femenino doméstico" (2001, p. 13).

10 Es el mismo artículo publicado en $L a$ Educanda: "La Historia á vista de pájaro" en dos entregas: no 54, 16-1-1864, pp. 11-13 y no 55, 24-1-1864, pp. 21-23.

11 Sobre esto escribe Alda Blanco: "La educación sería, pues, la apertura inicial hacia el espacio público porque daría pie a que las mujeres aprendieran los rudimentos del saber, se incorporaran paulatinamente al sistema educativo -principalmente a nivel de primera y segunda enseñanza- y se convirtieran en educadoras a través de la palabra escrita. El que así se vincularan lo público y lo privado parecía abrir el espacio público a la mujer -por lo menos teóricamente-, aunque en sus primeros momentos fuese un mero resquicio" (2001, p. 79).

12 Si bien se hace a modo de ejemplo para los niños responde a la misma intención con que se incluye este tipo de artículos en otras revistas femeninas con el caso de mujeres ilustres. Así a este respecto dice Iñigo Sánchez Llama: "existe una tendencia en la cultura impresa del siglo XIX que dignifica a la "mujer de talento" mediante gloriosos ejemplos de mujeres célebres del pasado o menciones a los benéficos efectos de "las buenas madres" en las trayectorias biográficas de los "grandes hombres" (2001, p. 44).

13 Joaquina García Balmaseda realizó una importante labor de traducción de novelas en La Correspondencia de España a partir de 1864 . Se puede consultar la lista de estas traducciones en M.a del Carmen Simón Palmer (1991, pp. 289290). También aparecen en nota $n=2$ del artículo de Dolores Thion SorianoMollá (2011, p. 384).

14 "La niña y las flores" ( $n$ o 3, 1857, pp. 34-35), cuento traducido de Mistris Critabel, irlandesa contemporánea, "Los huevos de Pascua" (no 8 a no 10, 1857) -también se publica este relato en $L a$ Educanda (no $126,16-7-1865$, pp. 205208 y no $128,129,130,132,133,134$ y $136,30-9-1865$, pp. 282-285)-, “Un sueño reparador" (no 43, 1858, pp. 221226, arreglado del francés); también en La Educanda (no46, 16-11-1863, pp. 263-266) y en La Voz de la Caridad ( $\mathrm{n}$ ㅇ 155, 15-8-1876, pp. 171-176). Traducidos de los Cuentos de Schmid son: "Los verdaderos amigos" (no 54, 1858, p. 95), "El gusano de luz" (no 55, 1858, pp. 108-110) y "El ama de gobierno de nueve años" (arreglado del francés). Otros cuentos son: "La vendedora de fósforos" (no 70, 1858, pp. 349-350) (traducción del cuento alemán), "La mariposa" (arreglo) (no 71, 1858, pp. 362-365) y "La cotorrita" (no 96, 1859, pp. 285-288).

15 Cf. Joaquina García Balmaseda (1884).

16 Catherine Jagoe (1998) dice respecto a la Ley Moyano de 1857:"Solo manda impartir en común a ambos sexos las primeras letras, matemáticas y religión; después, en el nivel primario superior, divergen los estudios, reservándose para los chicos la introducción a la agricultura, la industria, el comercio, la geometría, el dibujo lineal, la física y la historia natural. Para las chicas se prescriben clases de doctrina cristiana, lectura, escritura, gramática, aritmética y labores en la escuela elemental. Añadiendo dibujo para labores, higiene 
doméstica y "rudimentos" de historia y geografía españolas en los pocos colegios que ofrecían una enseñanza primaria superior a las niñas" (p. 118).

17 Como cuento traducido tenemos "Cendrillon. Cuento popular infantil" en tres entregas (2-6-1861, pp. 32-34; 9-6-1861, pp. 41-42; 8-7-1861, pp. 5356) -también aparece en La Educanda en dos entregas ( $n$ ㅇ 17, 8-4-1863, pp. $132-133$ y no $18,16-4-1863$, pp. 140 143)-. Asimismo como traducción tenemos "Memorias de una niña" (escrito en francés por Mlle. Julli Gouraud), en varias entregas desde julio a diciembre de 1861. En el primer artículo se hace referencia a una de las obras de esta autora publicada en Educación Pintoresca: "Memorias de una muñeca". Publica la traducción de "Memorias de una muñeca", de Mlle. Julli Gouraud y por entregas (no 20, 30-4-1863, pp. 158-59 y continúa en los no 21 a 32 (31-7-1863) en La Educanda.

18 La llustración de la Infancia: revista tipoautógrafa de educación y recreo. Revista semanal editada en Madrid en 1877 y dirigida por D. Carlos Luis de Cuenca. Parece que acaba en 1879. Aquí publica "La indolencia" (no 46, 15-12-1877, pp. 382 849), el mismo texto antes aparecido en Educación pintoresca, y "El prisionero. Diálogo en verso entre una madre y un hijo" (15-12-1877, pp. 362-363), que también aparece en la revista madrileña La niñez (III, marzo de 1880, p. 126).

19 La llustración de los Niños, revista quincenal madrileña fundada en 1878 y que acaba en 1883. D. José Novi y Pereda es su propietario y director.

20 La Floresta: periódico semanal dedicado esclusivamente [sic] al bello secso [sic]. Editado en Barcelona por Salvador Cutchet en 1857. Incluye un paratexto de La Bruyère: "La mujer es fácil de gobernar, si el hombre quiere ocuparse en dirigirla" (no 3).

21 Publicación dedicada a la enseñanza primaria y a la mujer, "revista quincenal de educación, enseñanza y amena lectura, dedicada a las maestras y madres de familia". Fundada y editada por José P. Galán, en diciembre de 1862 se funde con la empresa de El Correo de la Moda (1851-1886), apareciendo desde entonces como "periódico de señoritas, dedicado a las madres de familia, maestras y directoras de colegios".

22 "La gitanilla" en varias entregas ( $\mathrm{n}$ 2, 16-12-1862, pp.14-16, no 3, 24-12-
1862, pp. 22-24 y no 4 (31-12-1862, pp. 27-30); "Buena amiga", en varias entregas (no 7, 24-1-1863, pp. 53-54, nㅇ 8 , 31-1-1863, pp. 63-64, no 9, 8-2-1863, pp. $68-70$, no $10,16-2-1863$, pp. $78-80$ y no 11, 24-2-1862, p. 86); “Memorias de una muñeca", traducción de Mlle. Julli Gouraud y por entregas ( $\mathrm{n}$ - 20, 30-41863 , pp. 158-59 y continúa en los no 21 a 32, 31-7-1863); "Una mala tentación" (no49, 8-12-1863, pp. 390-392 y no 50, 16-12-1863, pp. 396-398). Los relatos traducidos y recogidos en esta revista que ya aparecieron en otras publicaciones anteriores han sido convenientemente señalados en sendas notas a pie de página en este artículo.

23 El Correo de la Moda, periódico de literatura, educación, teatros, labores y modas. Es una revista semanal que se crea en Madrid en noviembre de 1851. En 1853 se funda con Álbum de señoritas para formar Álbum de señoritas y Correo de la Moda.

24 Utiliza el segundo apellido de su madre, Francisca Balmaseda y Olivares. Sobre este tipo de seudónimo escribe Simón Palmer (1989): "Casi opuesto es el de aquellas que hubieran dado cualquier cosa por pertenecer a la aristocracia, en vista de lo cual decidieron adoptar un título como seudónimo. Así, Joaquina García Balmaseda", "La ocultación de la propia personalidad en las escritoras del siglo XIX» (p. 93).

25 Así describe en esta crónica las maravillas de la luz eléctrica: "Siempre se han dado en la Corte fiestas suntuosas, pero de seguro quedarían muy deslucidas en comparación con las modernas, donde los refinamientos de la industria y de las artes se ponen al servicio de los dueños de la casa en que se dispone el baile. Los que narraron las maravillas de las Mil y una noches, no presintieron el encantador efecto de la luz eléctrica, porque de adivinarle, no sé adónde hubieran ido á parar en sus descripciones. Dícese que la luz eléctrica favorece poco el semblante de la mujer, pero en cambio realza tanto su traje, sus joyas, su aire y sus maneras, produce ilusión tan fantástica entre las arboledas de un jardín, que difícilmente renunciarán a ella los que tengan que organizar una fiesta".

26 Esta misma actividad la realiza posteriormente en El oriente de Asturias (Llanes), en la sección del mismo nombre - "La vida en sociedad"- desde abril de 1899 a 18 de noviembre de 1900.
27 También en forma epistolar encontramos su artículo de El Correo de la Moda "Una carta perdida" (2-3-1886, p. 71), donde dice de la escritura femenina epistolar: "aunque haya adelantado mucho en este último tercio de siglo la educación de nuestro sexo, todavía son pocas las señoras que hacen papel airoso hablando y escribiendo sin tocar en los extremos de la frivolidad ó la pedantería".

28 Asimismo este tema es objeto del breve escrito publicado en Paris Charmant-Artístico: periódico ilustrado de las nuevas modas "Preparación de una comida" (11-1882, pp. 1-2)

29 Sobre este mismo tema escribe el artículo "La coquetería", aparecido en dos publicaciones: La madre de familia (5$12-1875$, pp. 161-162) y La Familia (no 24, 1875, pp. 188-189).

30 Joaquina García Balmaseda escribe "Lo que toda mujer debe saber", en forma epistolar, donde plasma estas mismas ideas. En el libro de Pilar Pascual de Sanjuán (1877, pp. 99-105).

31 Joaquina García Balmaseda también escribe "La actriz española”, en Sáez de Melgar (1881, pp. 63-77).

32 A este respecto resulta muy interesante su artículo en El Museo Universal "Derechos y deberes de la mujer" (28-111869, pp. 379-380), leído como conferencia en el Ateneo de señoras.

33 En la nota del artículo aparece: "En el primero, la que suscribe, leyendo en una sesión literaria y varias señoras, profesoras de educación, tomando parte en las discusiones del Congreso pedagógico. En el segundo, doña Adela Riquelme de Trechuelo, en una brillante conferencia para la mujer, en la que mostró vastísima ilustración y fácil palabra". Además el 28 de diciembre de 1868 Faustina Sáez de Melgar funda, ayudada por Joaquina García Balmaseda y Fernando de Castro, el Ateneo de Señoras, que cesa su actividad en junio de 1869. Su fin principal es "procurar la más alta instrucción de la mujer" (artículo de Joaquina García Balmaseda, 2-2-1869, en Sáez de Melgar (1869, pp. 25-29)). Y la participación de la Balmaseda en tertulias, círculos artísticos y literarios -como el Liceo Piquer- es constante según da testimonio de ello en textos de este mismo periódico como los publicados en las secciones "La vida en sociedad" y "Revista de Madrid". 
Blanco, A. (2001). Escritoras virtuosas: narradoras de la domesticidad en la España isabelina. Granada: Universidad de Granada.

García Balmaseda, J. (1860). La madre de familia. Diálogos instructivos. Madrid: Librería de la viuda de Hernando.

García Balmaseda, J. (1861). Genio y figura. Madrid: Imprenta de José Rodríguez.

García Balmaseda, J. (1868). Donde las dan..., Proverbio en un acto y en verso. Madrid: Establecimiento tipográfico de Eduardo Cuesta.

García Balmaseda, J. (1868 b). Entre el Cielo y la Tierra. Poesías. Madrid: M. CampoRedondo.

García Balmaseda, J. (1871). Un pájaro en el garlito. Comedia en un acto y en prosa. Madrid: Imprenta de José Rodríguez.

García Balmaseda, J. (1882). La mujer sensata. Educación de sí misma. Madrid: Imprenta de la Correspondencia.

García Balmaseda, J. (1884). La mujer laboriosa, novísimo manual de labores que comprende desde los primeros rudimentos de costura hasta las más frívolas labores de adorno. Barcelona: Librería Juan y Antonio Bastinos.
García Balmaseda, J. (1889). Historia de una muñeca escrita por ella misma: libro de utilidad y recreo para las niñas. BarceIona: Librería Juan y Antonio Bastinos.

García Balmaseda, J. (1907). Ecos de otra edad. Madrid: Ducazcal.

Jagoe, C. (1998). "La enseñanza femenina en la España decimonónica”. En Jagoe, C., Blanco, A. y Enríquez de Salamanca, C. La mujer en los discursos de género. Textos y contextos en el siglo XIX. Madrid: Icaria.

Pascual de Sanjuán, P. (1877). Epistolario manual para las señoritas: modelos de cartas para la niña, la joven y la mujer. Barcelona: Librería de Juan y Antonio Bastinos.

Sáez de Melgar, F. (1869). Memoria del Ateneo de Señoras. Madrid: Imprenta de Rojas.

Sáez de Melgar, F. (ed.). (1881). Las mujeres españolas, americanas y lusitanas pintadas por sí mismas. Barcelona: Juan Pons.

Sánchez Llama, I. (2000). Galería de escritoras isabelinas. La prensa periódica entre 1833 y 1895. Madrid: Cátedra.

Sánchez Llama, I. (2001). Antología de la prensa periódica isabelina escrita por mujeres, 1843-1894. Cádiz: Universidad de Cádiz.

Simón Palmer, M.C. (1983). «Escritoras españolas del siglo XIX o el miedo a la marginación». Anales de Literatura Española, 2, pp. 477-490.

Simón Palmer, M.C. (1986). "La mujer y la literatura en la España del siglo XIX". En Kossoff, D., Amor y Vázquez, J., Kossoff, R.H. y Ribbans, G.W. (eds.) Actas del VIII Congreso de la Asociación Internacional de Hispanistas. Madrid: Istmo, pp. 591-596.

Simón Palmer, M.C. (1989). «La ocultación de la propia personalidad en las escritoras del siglo XIX». En Neumeister, S. (ed.) Actas del IX Congreso de la Asociación Internacional de Hispanistas. Frankfurt am Main: Vervuert Verlag, 2, pp. 91-97.

Simón Palmer, M.C. (1991): «García Balmaseda, Joaquina», Escritoras españolas del siglo XIX. Manual bio-bibliográfico. Madrid: Castalia.

Thion Soriano-Mollá, D. (2011). "Joaquina García Balmaseda: una escritora isabelina al servicio de la mujer", Anales de Literatura Española, 23, pp. 381-403. 